\title{
Genetic Determinism, Technology Optimism, and Race: Views of the American Public
}

\section{Citation}

Hochschild, J., and M. Sen. 2015. “Genetic Determinism, Technology Optimism, and Race: Views of the American Public." The ANNALS of the American Academy of Political and Social Science 661 (1) (August 10): 160-180. doi:10.1177/0002716215587875.

\section{Published Version}

doi:10.1177/0002716215587875

\section{Permanent link}

http://nrs.harvard.edu/urn-3:HUL.InstRepos:30780208

\section{Terms of Use}

This article was downloaded from Harvard University's DASH repository, and is made available under the terms and conditions applicable to Open Access Policy Articles, as set forth at http:// nrs.harvard.edu/urn-3:HUL.InstRepos:dash.current.terms-of-use\#OAP

\section{Share Your Story}

The Harvard community has made this article openly available.

Please share how this access benefits you. Submit a story.

\section{Accessibility}




\title{
Genetic Determinism, Technology Optimism, and Race: Views of the American Public
}

\author{
Jennifer Hochschild and Maya Sen
}

April 2015

\section{Annals of the American Academy of Political and Social Sciences}

Issue on "Race, Racial Inequality, and Biological Determinism in the Genetic and Genomic Era," Edited by W. Carson Byrd and Matthew W. Hughey

Forthcoming September 201561 (1)

Correspondence to: Jennifer Hochschild, Harvard University, Department of Government, 1737 Cambridge St., CGIS Knafel Building 412, Cambridge, MA 02138; email:

hochschild@gov.harvard.edu; phone: 617.496.0181.

${ }^{1}$ Email: maya_sen@hks.harvard.edu.

Abstract: We begin with a typology of Americans' understanding of the links between genetic inheritance and racial or ethnic groups. The typology has two dimensions: one running from genetic determinism to social construction, and the other from technology optimism to technology pessimism. Construing each dimension as a dichotomy enables four distinct political perspectives on the possibilities for reducing racial inequality in the United States through genomics. We then use a new public opinion survey data to analyze Americans' use of the typology. Survey respondents who perceive that some phenotypes are more prevalent in one group than another due to genetic factors are disproportionately technology optimists.

Republicans and Democrats are equally likely to hold that set of views, as are self-identified blacks, whites, and Latinos. The article discusses the findings, and speculates about alternative interpretations of the fact that partisanship and group identity do not differentiate Americans in their views of the links between genetic inheritance and racial inequality. 
Keywords: genomics; technology optimism; public opinion; genetic determinism; social construction; race; partisanship

Jennifer Hochschild is Henry LaBarre Jayne Professor of Government and a professor of African and African American studies at Harvard University. Recent books include Do Facts Matter? Information and Misinformation in Democratic Politics (with Katherine Einstein; University of Oklahoma Press,2015) and Creating a New Racial Order: How Immigration, Multiracialism, Genomics, and the Young Can Remake Race in America (with Vesla Weaver and Traci Burch; Princeton University Press 2012).

Maya Sen is an assistant professor of public policy at Harvard University. Recent articles include “Identifying Judicial Empathy: Does Having Daughters Cause Judges to Rule for Women's Issues?” (with Adam Glynn); "How Judicial Qualification Ratings May Disadvantage Minority and Female Candidates"; and "Courting Deliberation: The Role of Deliberative Democracy in the American Judicial System." 
Challenges surrounding the design of large-scale genotyping projects ... illustrate the complexities and ambiguities associated with the use of group labels in genomic research. Depending on how we use this information, the potential exists to describe simultaneously our similarities and differences without reaffirming old prejudices.

- Rotimi $(2004,543)$

Genomics is already a multi-billion dollar industry and research program, and it is likely to continue growing exponentially. It enables everything from new dating services and testing the fish in sushi to convictions or exonerations in courts of justice, identifying victims of massacres, and finding cures for devastating rare diseases. It also risks genetic surveillance, a new eugenics, designer babies, and the loss of personal privacy. Genomic science raises philosophical issues of the meaning of human life, the boundaries of free will, the moral limits of scientific innovation, and responsibilities to one's children. Most relevant here, despite the fact that genes have no race, genomics is increasingly intertwined in Americans' understanding and practice of race and ethnicity.

As Charles Rotimi points out, "the use of group labels in genomic research" is indeed full of "complexities and ambiguities"-but as he well knows, that is simply the newest chapter in an old narrative. Americans have always expressed conflicting views about links between race and genetic inheritance. On one hand were the nineteenth-century polygenists who argued that blacks and whites were different species and debated whether the children of an inter-racial union would be "feeble-minded" or sterile, like mules (Banton 1998; Fredrickson 1987). On the other hand were those who believed, or hoped, that in America "individuals of all races are melted into 
a new race of man, whose labours and posterity will one day cause great changes in the world" (de Crévecoeur 1782/1981, 70).

A biological understanding of race has usually, though not always, been associated with implicit or explicit endorsement of group-based hierarchy, just as a social constructionist understanding has generally been associated with racial liberalism (Montagu 1942/1997; Morning 2011). The questions for this article are, How do Americans currently perceive links between genetic inheritance and race or ethnicity? How do they evaluate the societal role of genomic science? and How are those understandings related to group-based hierarchy? The importance of these questions lies in the possibility that Americans can use genomic science to develop a new framing for linking genomics and race or ethnicity "without reaffirming old prejudices"- as contrasted with the possibility that some Americans will use genomic science to recreate old tropes that portray other Americans as inherently, biologically different and inferior. Absent a crystal ball, we are limited to informed speculations in the conclusion about which possibility will have greater societal force. But even without answers, we want to make clear to readers the broad implications of the set of questions in this article about Americans' understanding of the links between genetic inheritance and race or ethnicity.

To address the questions of whether and how Americans link genetics and race, we first describe two conceptual dimensions. The first is cognitive, ranging from genetic determinism to social constructivist explanations of probabilistic differences among racial and ethnic groups. The second is affective, ranging from technology optimism to technology pessimism about societal uses of genomic science. Construing these dimensions as dichotomies enables us to construct a stylized $2 \times 2$ table, in which each cell presents a distinctive way to understand and evaluate the role of genetic explanations in societal discourse. In the second section, we use this 
typology to organize an analysis of a new public opinion survey with a focus on Americans' views of whether some diseases, traits, or behaviors are more prevalent in one racial or ethnic group $^{i}$ than others due to genetic factors. ${ }^{\text {ii }}$ In the third section, we discuss the results of that analysis to shed light on major social groupings' views of the links between genetics and race or ethnicity. We conclude with a discussion of possible directions for the politics of race, racial inequality, and inheritance in the genomic era.

\section{The Typology: Genetic Determinism x Technology Optimism}

\section{Genetic and environmental determinism}

The distinction between genetic inheritance and environmental determinism is more commonly known by the old rubric of "nature versus nurture."iii Roughly speaking, the concept of genetic determinism articulates the claim that important human phenotypes are caused or at least importantly shaped by inheritance. People are not automatons - both their volitions and the contexts in which they live matter - but they act within a more or less narrow range of genetically fixed options. An environmental determinist argues the opposite: most important human phenotypes are caused or at least profoundly shaped by socialization through societal forces. Again, people are not automatons — both genetic inheritance and individual volitions can have causal force in important arenas of life—but they perceive and act within a more or less narrow range of contextually available options.

One can frame the distinction between social constructivism and genetic determinism at various levels of analysis. A psychologist can see an individual's intelligence, weight, morality, or ambition as a result of genetic inheritance from parents and ancestors or as a result of choices shaped through socialization, interactions with others, mental patterns, or particular contexts or cues. A genetically deterministic sociologist might argue that members of a racial or ethnic 
group have disproportionately inherited a set of alleles that contribute to a particular athletic ability, style of learning, approach to social interactions, or at least that social categories and cultures map closely onto geographic bio-ancestry (Guo et al. 2014; Shiao et al. 2012; Wade 2014). A socially constructivist sociologist, in contrast, will emphasize access to resources, constraint and coercion, demographic and cultural context, and stratification systems in explaining group members' athleticism, learning style, or social interactions. Few analysts now embrace genetic determinism for whole societies or nationalities. But scholars ranging from $\mathrm{W}$. E. B. DuBois to Herbert Spencer sought at the turn of the twentieth century to explicate a society's essence or stage of evolutionary progress through its - metaphorical or literal— inheritance. Social constructivists in turn invoke history, particularities of geography or resources, migration patterns, and political interactions to explain differences across societies, or reject the idea altogether as too simplistic.

There is no necessary association between political liberalism or conservatism and genetic or environmental determinism. A genetic determinist might argue that children born with a propensity for aggression should be monitored and controlled, or that such children warrant extra care and resources given that their behavior cannot be construed as their own fault. Most progressives argue that sexual orientation is genetically determined but racial categories are socially constructed; conservatives argue the reverse (Garretson and Suhay 2014). Many geneticists fear that research on links between genomics and racial categories opens the door to a contemporary form of eugenics (Duster 2003), but many (sometimes the same people) reject "color-blind genomics" on the grounds that it not only is wrong scientifically but also perpetuates racial injustices and medical biases (Bliss 2012; Risch et al. 2002). Nonetheless, the usual association, whether imputed or chosen, is between social constructivism and liberalism (in 
the American sense) on one hand, and genetic determinism and political conservatism on the other (Suhay and Jayaratne 2012).

\section{Technology optimism and pessimism}

The distinction between technology optimism and pessimism also goes by several names_risk acceptance versus risk aversion, preference for Type I or Type II errors, or pejoratively, scientism. ${ }^{\text {iv }}$ Its core distinction is the degree to which an individual, group, or polity chooses, at the margin, to take risks in the hope that the benefits associated with the risky activity will outweigh the potential costs. The scientific or technology optimist "is centered on advancement concerns.... [He or she is driven] by motivations for attaining growth and supports eager strategies of seeking possible gains even at the risk of committing errors or accepting some loss." The pessimist, in contrast, "is centered on security concerns ... [and] supports vigilant strategies of protecting against possible losses even at the risk of missing opportunities of potential gains" (Hazlett et al. 2011, 77).

Like genetic determinism, technology optimism can be understood at several levels of analysis. Psychologists have shown that some individuals are by nature, or perhaps by socialization, cognitive biases, or interpersonal interactions, optimistic and open to new experiences, while others are cautious or committed to tradition or order (Carney et al. 2008). Sociologists have shown that members of groups with deep experiences of oppression or privilege tend to differ in their assumptions of whether the social or even natural world is fundamentally benign or malign (Urban and Hoban 1997). Policy analysts observe that a technologically optimistic institution or policy will promote research and development, minimize regulation, and create incentives for innovative practices, whereas a pessimistic institution or policy will require strict oversight, set high barriers to licensure, and focus on safeguards to 
protect the vulnerable. One can even look at systems of governance through this lens: the American constitutional structure with its multiple veto points, strong courts, and many layers of quasi-independent governments is very risk averse, in contrast to a parliamentary system with a centralized government, one-party control, and less explicit safeguards for rights (Lijphart 1977). Whether technology optimists or pessimists are more likely to be liberal or conservative is a fascinating question. Albert Hirschman depicts reactionaries as technology pessimists (although not with that term): they resist proposals for political reform because efforts to improve society are futile in the face of massive inertia, are likely to jeopardize gains already made, and will have unintended consequences that worsen the problem at hand. Liberals, in contrast, are optimists; they focus on "reasons why a new and an older reform will interact positively rather than negatively," and they seek out "the welcome assurance that the world is 'irrevocably' moving in some direction they advocate” (Hirschman 1991, 151, 155XX). [?/Please provide page \#s] Hirschman's characterization seems generally accurate. In the 2012 American National Election Study, for instance, three-fifths of liberals, compared with just over a quarter of conservatives, agreed that government should usually use the scientific method to solve important problems (see also Binder 2002; Gauchat 2012; Mooney 2005).

But Hirschman's characterization of the links between liberals and innovation does not always hold. Surveys show liberals in some cases to be more pessimistic than conservatives about the societal uses of new science or technology. Examples include the use of nuclear power for energy, deployment of unmanned drones, techniques for government surveillance, childhood vaccinations, and aspects of genomic science such as genetically modified organisms or forensic biobanks.

A typology 
The relationships of genetic determinism to social constructivism and of technology optimism to pessimism are better understood as continua rather than dichotomies. That is, probably most experts hold positions closer to the centers than to either extreme; they see a balance between potential gains and risks of scientific or technological innovation, or they argue that complex, nonlinear interactions between genetic inheritance and social context best explain many phenotypes (Goodman et al. 2003; Moore 2015; Simons et al. 2011). Nonetheless, for the sake of clarity in interpretation of the survey results and because the general public tend to hold less sophisticated views than do experts, this article treats the continua as dichotomies.

Putting the two dimensions together permits a $2 \times 2$ table, with distinctive and internally coherent understandings of race and racial inequality in each cell, as shown in Table 1. [?/In your original submission, this was referred to as "Figure 1", but you have another, true figure in the paper, to which you also referred as Figure 1. Because this has "cells" table is more appropriate label for ANNALS. Table numbers changed appropriately throughout OK, thx. ] Cell 1 was more prominent in public discourse a century ago. Madison Grant's popular 1916 book, The Passing of the Great Race, argues that the three European races-Nordic, Mediterranean, and Alpine_-"vary intellectually and morally just as they do physically. Moral, intellectual and spiritual attributes ... are transmitted substantially unchanged from generation to generation" (Grant 1916, 226). Although a social pessimist, Grant was a technology optimist: "as soon as the true bearing and import of the facts [that is, "the continuity of physical traits and the limitation of the effects of environment to the individual"] are appreciated by lawmakers, a complete change in our political structure will inevitably occur" (p. 262).

[Table 1 about here] 
Richard Herrnstein and Charles Murray are prominent, more contemporary, residents of cell 1. They find that test scores of American blacks and whites differ by about fifteen IQ points. As a result, "a legitimate scientific debate on the topic [of "the relationship of genes to race differences in intelligence"] is underway; it is scientifically prudent at this point to assume that both environment and genes are involved, in unknown proportions" (Herrnstein and Murray 1996, 562-63). They are cautious technology optimists: "raising intelligence significantly, consistently, and affordably would circumvent many of the problems that we have described. Furthermore, the needed environmental improvements—-better nutrition, stimulating environments for preschool children, good schools thereafter—seem obvious. But raising intelligence is not easy" (p. 389; see also Crow [2002]; Wade [2014]).

Cell 2 is largely occupied by geneticists who are acutely aware of racial inequality, or even work as geneticists because of their awareness of and concern about group-based inequality. Catherine Bliss elegantly captures this viewpoint:

[To some scientists,] race-free genomics is the same as the colorblind rhetoric that contributed to racism in the South. ... [One interview subject] conceptualizes race as biologically and socially meaningful in ways that demand immediate attention from genomics. ... Scientists envision the field's role as both a corrective to the prior socially constructed scientific engagement with race, and an arm of a broader racial consciousness-raising front (Bliss 2012, 171).

In this view, for example, analyzing the genetic bases of diseases that disproportionately affect members of a particular racial or ethnic group (e.g. diabetes, high blood pressure, asthma, some forms of cancer), or the genetic reasons that some diseases tend to present differently across different groups, or the genetic underpinnings of group-inflected differential responses to treatment regimens are all ways to use this new science to alleviate long-standing racial and ethnic inequalities in health and health care. 
Most scholars in the field of racial and ethnic studies occupy cell 3. They argue that concepts of race and ethnicity and distinctions among individuals are socially constructed; linking genomics to race risks treating invented categories as scientific truths, and even risks revival of the old pseudo-science of eugenics. Jonathan Kahn, for example, argues that "new diagnostic and therapeutic interventions may reflect or be mapped upon existing social categories of race, class, gender, and ethnicity in a harmful or dangerous manner. At the most basic level, the politics of the meantime in pharmacogenetics may be promoting ... the scientifically unjustified and social dangerous recasting of race as a social and historical construct into a reified genetic category" (Kahn 2012, 873-74; see also Roberts 2011; Fullwiley 2007; Sternberg et al. 2005). In this view, genomic science falsely depicts racial groups as having a significant genetic component, even if scientists themselves proclaim race to be a socially constructed concept. The development of genomics in research and medicine risks further reifying this mistake.

Finally, cell 4 is occupied by genomicists and others who reject a strong link between genetics and race but nonetheless believe that genomic science can help to reduce racial inequality. The National Institutes of Health's self-presentation in its Strategic Research Plan and Budget to Reduce and Ultimately Eliminate Health Disparities is a good example. The NIH supports "research to understand biological, socioeconomic, cultural, environmental, institutional, and behavioral factors affecting health disparities" (NIH 2002, 1). Nine of the ten items on its list of causes of group-inflected health and mortality disparities are social or environmental; one is "biological factors" (p. 15). Among other recommendations or ongoing programs to reduce racial and ethnic health disparities, the Plan describes the National Human Genome Research Institute's [?/Spell out on first use] "research objective" of "study[ing] 
genetic factors that contribute to diseases disproportionately affecting minority populations," and another institute's" [?Spell out on first use] plan to "combine genetic linkage data from collaborating research groups and identif[y] regions of the human genome that show evidence for linkage in type 2 diabetes" (p. 26). That is, even the governmental agency that conducts or funds most genomics research portrays itself as predominantly committed to social constructivism, along with being optimistic about the use of genomics to promote health and health equity. ${ }^{\mathrm{vi}}$

This typology, with its four substantively distinct cells, provides the structure for analyzing the new survey on Genomics: Knowledge, Attitudes, and Policies (GKAP), to which we now turn.

\section{GKAP Survey}

GKAP is an online 20-minute survey conducted in May 2011, by Knowledge Networks Inc. (now part of GfK), of 4,291 randomly selected U.S. adults. The survey was stratified by the racial or ethnic group with which respondents had identified when they joined the Knowledge Networks panel, typically months or years earlier. ${ }^{\text {vii }}$ GKAP included 1,143 non-Hispanic whites, 1,031 non-Hispanic African Americans, 337 non-Hispanic Asians, 1,096 Hispanics (roughly half of whom chose to take the survey in Spanish), and a small number of other groups. The full set of respondents is weighted appropriately so as to reflect the United States population; when relevant, we weight by particular racial or ethnic groups.

GKAP included 111 questions ranging from items designed to assess respondents' knowledge about basic genomic science to items querying support for funding and regulation of genomics research, views about various aspects of genomic science, trust in scientists and public officials, and preferences about further development of the science. Question order and the order 
of response categories were frequently randomized to avoid response bias. Note, however, that respondents were told at the outset that the survey would inquire as to their beliefs about genomics and genomic science, which might have had a priming effect about the importance, difficulty, or controversial nature of the issue.

For this article we analyze responses to two sets of GKAP questions: on perceptions that certain phenotypes are highly prevalent in a particular racial or ethnic group due to genetic inheritance, and on pessimism or optimism about the impact of societal use of particular forms of genomics research. We describe each set of items in turn.

\section{Group-inflected genetic inheritance}

To measure respondents' views of whether certain allele frequencies are higher in one group than in others, GKAP asked:

Some things about a person may be genetically connected to their race or ethnicity. Other things may be due to their environment or the way they live. As far as you know, how much does each of the following have to do with a person's race or ethnicity compared with the person's environment or lifestyle?

Respondents were presented with eight human phenotypes. One (the flu) results from person-toperson contagion; three occur disproportionately, although not exclusively, in conventionally defined racial or ethnic groups (sickle cell anemia, cystic fibrosis, and “particular eye color”), and four ("level of intelligence," heart disease, "being gay or lesbian," and "being aggressive or violent") are open to a variety of interpretations. The survey asked respondents to gauge whether each item had "all or almost all to do with environment or lifestyle," was caused by a "mixture of race/ethnicity and environment or lifestyle," or had "all or almost all to do with race or ethnicity." A small portion (fewer than 5 percent) of respondents refused to answer some or all of the questions; these individuals were dropped from the analysis. 
To create a summary measure across all questions, we ordered each answer from (1) those having a basis in theenvironment or lifestyle to (2) those originating in a mixture to (3) those having almost all to do with race or ethnicity. We added the person's answers and took the average, which yielded a single value representing each respondent's perceptions across the eight items. Given three answer categories, the scale ranged from one to three; a high value indicates a strong perception of phenotypes being more highly prevalent in one group due to genetic factors, whereas a low value indicates a strong perception of environmental or individual determinants of differences in the prevalence of these traits, behaviors, or diseases across groups.

Table 2 provides summary statistics for this group-inflected genetic inheritance index for the whole sample, and disaggregated by political party (Democrat or Republican) and by selfidentified racial or ethnic group (white, black, Hispanic, Asian American). The respondents as a whole are ambivalent about the extent of group-inflected genetic inheritance, as indicated by a mean response of two out of three on the inheritance index. That is not an intrinsically meaningful number, since the aggregated responses may be a function of the fact that the eight items included three inherited, four ambiguous, and one nonheritable phenotype. What is more substantively meaningful is that views on group-inflected genetic inheritance are not partisan, and they vary only somewhat by racial or ethnic group, with whites most likely and blacks least likely to perceive group-inflected genetic inheritance.

[Table 2 about here]

\section{Technology optimism and pessimism}

GKAP measures the distinction between technology pessimism and optimism through four questions asking whether a given application of genomic science would do "more harm than good to society," "equal amounts of harm and good to society," or "more good than harm to 
society." The questions asked for views on: (1) "research on inherited diseases especially likely to affect people of one racial or ethnic group"; (2) "development of genetic tests to determine an individual's likelihood of getting an inherited disease"; (3) "use of DNA samples collected from patients for scientific or medical research"; and (4) "use of DNA samples collected from people convicted of a serious crime for law enforcement purposes."

We created an index of responses to these items analogous to the one for group-inflected genetic inheritance by ordering each answer from (1) more harm than good to (2) equal amounts to (3) more good than harm. We added the person's answers and took the average, which yielded a single value that represented each respondent's level of technology optimism across the four questions. Given three answer categories, the scale ranged from one to three; a high value indicates strong optimism, whereas a low value indicates strong pessimism about the societal uses of genomic science.

Table 3 presents summary statistics on this variable, again for the full sample and disaggregated by respondent's political party and self-identified racial or ethnic group. The GKAP sample as a whole is relatively optimistic about genomic science, as is each disaggregated group. Compared with Republicans, Democrats express somewhat greater confidence in the social benefits of genomic science. Whites and Asian Americans are the most optimistic, while blacks and Latinos are roughly tied at a somewhat lower but still positive level.

[Table 3 about here]

\section{Associations between Group-Inflected Genetic Inheritance and Technology Optimism}

We now come to the article's central empirical question: How does the perception that certain phenotypes are especially prevalent in some group(s) due to genetic inheritance link to levels of technology optimism about social uses of genomic science? More pointedly, are genetic 
determinists more likely to believe that genomic science is societally irrelevant or harmful, or that genomics can help to compensate for inherited problems? Conversely, are environmental determinists more likely to see genomic science as irrelevant or threatening to efforts to overcome socially constructed inequalities, or to see ways that genomics can contribute to such efforts? And do any or all of these views vary systematically in accord with political partisanship or racial and ethnic groupings?

We begin to answer those questions through a graphical representation of the relationship between the two indices. Figure 1 presents the group-inflected genetic inheritance index on the $X$-axis and the genetic optimism index on the $Y$-axis. (Because many of the points overlap, we "jitter" the observations to make it easier to absorb the information.) We contextualize the findings by superimposing lines that indicate the mean value of the inheritance variable (the straight vertical line; see Table 2), the mean value of the optimism scale (the straight horizontal line; see Table 3), and a diagonal line depicting a weighted least squares regression estimated line, where optimism is the outcome variable regressed onto group-inflected inheritance as the explanatory variable. This regression analysis uses the nationally representative survey weights. The figure includes all GKAP respondents, except for a small fraction who did not answer any one of the optimism or determinism questions.

[Figure 1 about here]

The density of the points depicts where respondents fall. Many score fairly high on both the group inheritance scale and the optimism scale; that is, they are in cell 2 of the typology depicted in Table 1. The weighted regression line shows a positive relationship between optimism and group-inflected inheritance; the greater the number of phenotypes that a respondent thinks are disproportionately present in one group due to genetic factors, the more 
likely he or she is to express optimism about the societal benefits of genomics research. This relationship is formalized via the regression analyses presented in Table 4, which show that this simple bivariate relationship is statistically significant at the 5 percent level.

Interpreting Figure 1 is not obvious, since we can show no causality in these correlational relationships. However, it seems most logical that respondents first develop a cognition on whether certain groups are likely to have a higher allele frequency on some phenotype(s) than other groups, and then develop an affect about the possible societal benefits of research in genomic science. ${ }^{\text {viii }}$

\section{Partisan identification}

Political activists or experts often passionately disagree over whether particular phenotypes appear disproportionately in one racial or ethnic group and if so, whether that is because of genetic inheritance or some other cause. We noted above that perceptions of groupinflected genetic inheritance are often associated with conservative politics. Conversely, social constructivist explanations of the disproportionate appearance of certain phenotypes in one or another group are usually linked to self-defined progressivism. Disagreements over appropriate levels of technology optimism are similarly often politicized in elite or activist discourse. Technology or science optimism is usually understood as a property of liberals, while conservatives typically express caution or pessimism about scientific innovation (see citations in "The typology" section).

The American public, however, is almost by definition less scientifically literate and less ideologically sophisticated than are experts and political elites. We can usefully ask, therefore, whether the links between technology optimism and perceptions of group-inflected genetic 
inheritance are similarly politicized in broad American public opinion. In the GKAP survey, the answer is "no."

After disaggregating self-defined Democratic and Republican survey respondents (including "leaners"), we fit weighted least squares regressions separately for each partisan identification. We find a positive relationship for both sets of partisans between perceptions of high allele frequency for certain phenotypes in a particular group(s) and optimism about the societal impact of genomics research (scatterplot not shown). Table 4 shows the results in a weighted least squares analysis that disaggregates the relationship by partisan identification (columns 2 and 3) and then shows the effect of an interaction between perceptions of groupinflected genetic inheritance and party identification (row 3).

[Table 4 about here]

Row 1 shows the essentially identical positive relationship between technology optimism and perceptions of group-inflected genetic inheritance among all respondents, Democrats, and Republicans. Row 3 demonstrates statistically what we see in row 1: there is no significant difference between Democrats and Republicans in their view of the links between groupinflected genetic inheritance and technology optimism. Partisan identification explains almost none of the variance in responses (the adjusted $\mathrm{R}^{2}$ is almost zero). In sum, although most extant scholarship and the views of most political advocates or elites engaged in this issue would lead us to expect differences between Democrats and Republicans, the association between perceptions of group-inflected genetic inheritance and technology optimism has no partisan valence in the American public.

Racial or ethnic self-identification 
Even if Democrats and Republicans do not politicize links between group-inflected genetic inheritance and the societal impact of genomic science, perhaps other socially defined groups differ in how they make these links. The most obvious groups to compare, and the ones most relevant to this issue of the ANNALS, are those comprised by racial or ethnic identity. As we saw in Tables 2 and 3, the four groups do vary slightly on both the genetic inheritance and technology optimism indices; the question now is whether those two indices interact differentially by racial or ethnic identity.

To answer that question, we performed a third analysis parallel to those already done on the whole GKAP sample and on partisan identifiers, in this case dividing the sample by racial and ethnic self-identification. (Our analyses in this section use separate weights for each racial or ethnic group.) Three of the four groups show the same positive relationship between the two indices that we have already seen among Democrats, Republicans, and the whole sample; Asians, however, show a statistically insignificant negative relationship (scatterplot not shown).

Table 5 provides a regression analysis similar to that in Table 4, using the index of genomics optimism as the outcome variable. Row 1 shows the strongest association between the two indices among African Americans, followed by Hispanics and whites, and a negative association among Asian Americans. That is, blacks who perceive a high degree of groupinflected genetic inheritance are even more technologically optimistic than are Hispanics or whites who see group-inflected genetic inheritance — not a result one would have expected from most understandings of social constructivism. Furthermore, row 5 shows a nonsignificant interaction between respondent's race (black) and belief in group-inflected genetic inheritance, suggesting that blacks do not differ from whites in their views of this phenomenon. The same holds for Latinos (row 6); Asian Americans are, however, less likely (at the 10 percent level of 
significance) than whites to be in quadrant 2 (row 7). As with partisan identification, racial or ethnic identification explains almost none of the variance in responses (the adjusted $\mathrm{R}^{2} \mathrm{~s}$ are close to zero).

[Table 5 about here]

In sum, although scholarship and elite or advocacy group discourse would lead us to expect a stronger link between genetic determinism and genomics optimism among whites than among nonwhite groups, that is not what GKAP shows. If anything, blacks express the strongest positive association, while Asians are the only group to show a negative association.

\section{Evaluating the Findings}

Results

The GKAP analysis shows several important results. First, ordinary Americans are able to make coherent and reasonable judgments about group-inflected genetic inheritance. Fewer than five percent perceived the flu to be more prevalent in one group than another due to genetic factors; between 40 and 80 percent did perceive sickle cell anemia, cystic fibrosis, and a particular eye color to be more prevalent in one group than another due to genetic factors. Their responses to the four ambiguous traits or behaviors were appropriately cautious, ranging from 6 to 18 percent perceiving that groups varied on these phenotypes due to genetic factors. Groups differed little in their ordering of the eight phenotypes from most to least associated with genetic inheritance in a group, and the proportion who agreed that a given phenotype had "all or most to do with race or ethnicity" differed little across groups (for more on these points, see Hochschild and Sen [forthcoming 2015]). .

In the second important result, although responses were distributed in all four cells of the typology of Table 1, cell 2-which combines perceptions of genetic determinism with 
technology optimism about genomics - predominated. It is beyond the scope of this article to explore respondents' reasons for this view, but the finding is fairly strong and robust. It warrants further investigation.

\section{Nonresults}

What GKAP did not show is perhaps as interesting as what it did. Social scientists are generally dismayed at the all-too-frequent finding of "no relationship at $\mathrm{p}<0.05$ " when analyzing associations among variables;biases in knowledge resulting from "the file drawer problem" of not publishing nonsignificant results are well known (Rosenthal 1979; Koricheva 2003; Egger and Smith 1998). In fact, support for the null hypothesis can be as substantively important as are findings that reject the null hypothesis (Kyzas et al. 2007; Miguel et al. 2014), and the GKAP evidence of few inter-group differences is worth careful consideration.

Nonfindings are intriguing only if one has strong reason to suspect that a relationship exists and that it matters. That is the case for the study of race and genetic determinism in the genomic era, as this issue of the ANNALS attests. The editors anticipate that the contributors will find links between the expansion of genomic science and "the re-emergence of biological deterministic arguments that influence ... public perspectives of social issues.” They expect these links to be deeply problematic because "biological determinism places an inordinate amount of attention to the ... genetic factors that influence a person's choices and position in society." These "sociobiological perspectives ... [can] reify social constructs such as 'race' and justify hierarchy and inequality" (Byrd and Hughey, this volume).

In that framing, the GKAP finding that many Americans reside in cell 2-perceiving that one or another group has a high allele frequency of some phenotypes and expressing optimism about the societal uses of genomic science - may be alarming. Since the indices themselves were 
socially constructed and thus could have shown different results if different questions or response categories had been offered, comparisons across groups defined by partisanship or selfidentified race and ethnicity are more substantively meaningful than the absolute value of either index. Here is where the nonresults become important:

Democrats do not differ from Republicans, and (with one possible exception) the four racial and ethnic groups do not differ from one another.

Speculations about the nonresults

We see two opposite ways to interpret this meaningful lack of difference by partisanship or self-identified race or ethnicity. On one hand, ordinary Americans may not understand the societal risks of both agreeing that the high prevalence of certain phenotypes in some groups is due to genetic factors and endorsing further development of genomic science. After all, they are taught about group-inflected allele frequencies in high schools; "U.S. texts are much more likely to expose students to essentialist understandings of race than to promote the idea that race is socially constructed" (Morning 2011, 68). They are further exposed to group-inflected genetic inheritance, along with some teaching about social construction, in colleges; "the view that 'there are biological races in the species Homo sapiens still holds an important place in contemporary social and biological science" as expressed by professors and researchers (Morning 2011, 104).

Furthermore, popular science books tend to promote the possibilities and benefits of genomic science, as do companies providing genetic ancestry tests and the widely viewed, award-winning PBS television series hosted by Henry Louis Gates Jr. A few, almost randomly chosen, book titles include Finding Oprah's Roots: Finding Your Own; Welcome to the Genome; When a Gene Makes You Smell Like a Fish; The Language of Life; and Drugs, Sex, and DNA. Small wonder, then, that in the absence of widely disseminated cautions about linking race and 
genetic inheritance, many Americans in all partisan or racial groups accept the idea of genetic determinism, are enthusiastic about the possibilities of genomic science, and link the two concepts together.

If this is the correct interpretation of the GKAP results, scholars and activists concerned about racial inequality and biological determinism in the genomic era have an educational task. Americans need to be taught that genetic determinism, as intentionally or inadvertently reinforced by promoters of genomic science, undervalues historical and environmental explanations for individual and group disadvantage. They need to be taught that race and ethnicity are social constructs, that group-based hierarchies and even undesirable phenotypes are learned and can be unlearned, that diseases such as sickle cell anemia afflict people who live in a particular geographic region rather than members of a particular racial group, and that science too often reinforces rather than undermines injustice and hierarchy.

There is, however, another way to understand the GKAP results. Perhaps Americans, even people of color, have become willing and able to separate the fact of group-inflected allele frequencies from the social and political practice of racial hierarchy. That is, perhaps the longstanding harmful associations between genetics and groups, captured by the terms "racial science" and eugenics, need no longer function to naturalize and justify racial and ethnic inequality. Many geneticists are insistent about just such a separation between what they understand to be genetic facts and what they clearly perceive to be racially unjust social practices. In fact, "people working in institutionally distinct realms of science and politics have now come to unite over tactics like the strategic use of a biologically essentialist definition of race. ... They are cooperatively interacting to create new research frameworks, expertise, and avenues for being human. The result is a widely accepted system of shared values and practices, 
and a consensus that race is meaningful socially and biologically" (Bliss 2012, 5). Even more strongly, to some scientists and social activists, "refusing to recognize the biological processes involved with race is seen as tantamount to scientific racism" (Bliss 2012, 90). ${ }^{\mathrm{ix}}$

The geneticists' concept of race-positive genomics has surely not moved into the public arena in any substantively powerful way. But perhaps some Americans are intuitively creating a lay version of this stance. The genealogical hobby of DNA ancestry testing is, from this perspective, not a misleading reification but rather a way to generate race-positive links among genetic inheritance, racial identity, genomic science, and personal gratification. As one DNA ancestry testing company puts it, "African Ancestry determines specific countries and—more often than not—-specific ethnic groups of origin with an unrivaled level of detail, accuracy and confidence. African Ancestry is committed to providing a unique service to the black community by working daily to improve the cultural, emotional, physical, spiritual and economic wellbeing of people across the African Diaspora." ${ }^{x}$

The search for cures to dangerous diseases might be another avenue into race-positive uses of genomic science. If researchers have sufficient confidence in recent findings, for example, that genetic inheritance contributes to nocturnal asthma among those with African ancestry (Levin et al. 2014), or partly explains the disproportionate prevalence of Type 2 diabetes in Mexico (SIGMA Type 2 Diabetes Consortium 2014), then scientists have "the potential to illuminate pathophysiology, health disparities, and the population genetic origins of disease alleles" (SIGMA Type 2 Diabetes Consortium 2014, 97).

Crucially for this perspective, blacks, Latinos, and (presumably liberal) Democrats- the people whom one would expect to be most wary of the societal use of research on groupinflected genetic inheritance - are indistinguishable from Republicans and whites in their 
likelihood of residing in cell 2 of the typology. That suggests that in the public mind, color-blind genomics is not necessary to avoid the old pernicious racial science.

If this is the correct interpretation of the GKAP results, scholars and activists concerned about racial inequality and biological determinism in the genomic era have a learning, not an educational, task. Perhaps ordinary Americans, along with race-positive scientists and activists, can teach social constructivists that one need not insist on only historical and environmental explanations for individual and group disadvantage in order to ameliorate racial inequality. To make the point in our typological framework, perhaps group-inflected genetic inheritance and social constructivism need not be political antagonists.

The results reported here do not allow us to adjudicate between these very different interpretations of the GKAP findings. More analyses of these data will be illuminating; for example, do controls for education, scientific literacy, or immigration status change the pattern of results within or across partisan or racial lines? More fundamentally, we cannot be sure that the GKAP items genuinely capture Americans' real views on technology optimism, genomic science, or biological determinism — or even if Americans have real views on such issues. These concepts are complex, seldom used in common discourse, and difficult to operationalize; if ever a research result needed to be replicated, that is the case here. However, until more research is completed, we conclude that many Americans who perceive group-inflected genetic inheritance also believe that genomic science can benefit society, and that liberals and members of disadvantaged groups hold that set of convictions to the same extent as conservatives and members of advantaged groups. 


\section{References}

Banton, Michael. 1998. Racial theories. New York, NY: Cambridge University Press.

Binder, Amy. 2002. Contentious curricula : Afrocentrism and Creationism in American public schools. Princeton, NJ: Princeton University Press.

Bliss, Catherine. 2012. Race decoded: The genomic fight for social justice. Stanford, CA: Stanford University Press.

Byrd, W. Carson, and Matthew Hughey. 2015. Overview of Special Issue on "Race, Racial Inequality, and Biological Determinism in the Genetic and Genomic Era." The ANNALS of the American Academy of Political and Social Science (this volume).

Carney, Dana, John Jost, Samuel Gosling, and Jeff Potter. [?/The ANNALS lists up to 10 authors; please add full first name and last name for 9 more authors] 2008. The secret lives of liberals and conservatives: Personality profiles, interaction styles, and the things they leave behind. Political Psychology 29 (6): 807-40.

Crow, James. 2002. Unequal by nature: A geneticist's perspective on human differences. Daedalus: 131 (1)[?/Volume or issue number required]: 81-88.

de Crévecoeur, J. Hector St. John. 1782/1981. Letters from an American farmer and sketches of eighteenth-century America. New York, NY: Penguin Classics.

Duster, Troy. 2003. Backdoor to eugenics. 2nd ed. New York, NY: Routledge.

Egger, M., and G. D. Smith. 1998. Bias in location and selection of studies. British Medical Journal 316 (7124): 61-66. [?/Please provide first names of authors, unless initials used on original publication]JLH: initials are in original publication

Epstein, Steven. 2007. Inclusion: The politics of difference in medical research. Chicago, IL: University of Chicago Press. 
Fredrickson, George. 1987. The black image in the white mind: The debate on Afro-American character and destiny, 1817-1914. Hanover, NH: Wesleyan University Press.

Fullwiley, Duana. 2007. The molecularization of race: Institutionalizing human difference in pharmacogenetics practice. Science as Culture 16 (1): 1-30.

Garretson, Jeremiah, and Elizabeth Suhay. 2014. How motivated reception of scientific communication polarizes the public: Biological attributions for homosexuality and the politics of gay rights. Washington, DC: American University, Department of Government. [?/What kind of publication is this?]JLH: it is a working paper, http://sites.lafayette.edu/suhaye/files/2014/02/Politics-of-biological-attribution-forsexual-orientation-021814.pdf

\section{Also listed on Suhay's cv}

Gauchat, Gordon. 2012. Politicization of science in the public sphere: A study of public trust in the United States, 1974 to 2010. American Sociological Review 77 (2): 167-87.

Goodman, Alan, Deborah Heath, and M. Susan Lindee,eds. [?/Please list remaining editors by full name] 2003. Genetic nature/culture: Anthropology and science beyond the twoculture divide. Berkeley, CA: University of California Press.

Grant, Madison. 1916. The Passing of the great race; or, the racial basis of European history. New York, NY: C. Scribner.

Guo, Guang, Yilan Fu, Hedwig Lee, Tianji Cai, Kathleen Mullan Harris, and Yi Li. [?/The ANNALS lists up to 10 authors; please add full first name and last name for 9 more authors] 2014. Genetic bio-ancestry and social construction of racial classification in social surveys in the contemporary United States. Demography 51 (1): 141-72. 
Hazlett, Abigail, Daniel Molden, and Aaron Sackett. [?/The ANNALS lists up to 10 authors; please add full first name and last name for 9 more authors] 2011. Hoping for the best or preparing for the worst: Regulatory focus and preferences for optimism and pessimism in predicting personal outcomes. Social Cognition 29 (1): 74-96.

Herrnstein, Richard, and Charles Murray. 1996. The bell curve: Intelligence and class structure in American life. New York, NY: Free Press.

Hirschman, Albert. 1991. The rhetoric of reaction: Perversity, futility, jeopardy. Cambridge, MA: Harvard University Press.

Hochschild, Jennifer, and Maya Sen. forthcoming 2015. Americans' attitudes on racial or genetic inheritance: Which is more predictive? in Kazuko Suzuki and Diego von Vacano, eds. Reconsidering race: Social science and racial categories in the age of genomics. Oxford University Press.

Kahn, Jonathan. 2012. The troubling persistence of race in pharmacogenomics. Journal of Law, Medicine and Ethics 40 (4): 873-85.

Koricheva, Julia. 2003. Non-significant results in ecology: A burden or a blessing in disguise? Oikos 102 (2): 397-401.

Kyzas, Panayiotis,Despina Denaxa-Kyza, and John Ioannidis. [?/The ANNALS lists up to 10 authors; please add full first name and last name for 9 more authors] 2007. Almost all articles on cancer prognostic markers report statistically significant results. European Journal of Cancer 43 (17): 2559-79.

Levin, Albert, Yun Wang, Karen Wells, Badri Padhukasahasram, James Yang, Esteban Burchard, and L. Keoki Williams. [?/The ANNALS lists up to 10 authors; please add full first name and last name for 9 more authors, and add first name of first author] 2014. 
Nocturnal asthma and the importance of race/ethnicity and genetic ancestry. American Journal of Respiratory and Critical Care Medicine 190 (3): 266-73.

Lijphart, Arend. 1977. Democracy in plural societies: A comparative exploration. New Haven, CT: Yale University Press.

Miguel, E.,C. Camerer, K. Casey, J. Cohen, K. M. Esterling, A. Gerber, R. Gennerster, D. P. Green, M. Humphries, G. Imbens et al. [?/The ANNALS lists up to 10 authors; please add full first name and last name for 9 more authors] 2014. Promoting transparency in social science research. Science 343 (6166): 30-31. JLH: first names not included in publishes article

Montagu, Ashley. 1942/1997. Man's most dangerous myth: The fallacy of race. Walnut Creek, CA: AltaMira Press.

Mooney, Chris. 2005. The Republican war on science. New York, NY: Basic Books.

Moore, David.2015. The developing genome: An introduction to behavioral epigenetics. New York, NY: Oxford University Press.

Morning, Ann. 2011. The nature of race: How scientists think and teach about human difference. Berkeley, CA: University of California Press.

National Institutes of Health. 2002. Strategic research plan and budget to reduce and ultimately eliminate health disparities. Washington, DC: U.S. Department of Health and Human Services. Available from http://www.nimhd.nih.gov/documents/VolumeI_031003 EDrev.pdf.

Risch, Neil, Esteban Burchard, Elad Ziv, and Hua Tang. [?/The ANNALS lists up to 10 authors; please add full first name and last name for 9 more authors] 2002. Categorization of 
humans in biomedical research: Genes, race, and disease. Genome Biology 3 (7):

p.comment2007.1-comment2007.12. [?/Page range or doi required; please provide]

Roberts, Dorothy. 2011. Fatal invention: How science, politics, and big business re-create race in the twenty-first century. New York, NY: New Press.

Rosenthal, Robert. [?/Please provide first name] 1979. The "file drawer problem" and tolerance for null results. Psychological Bulletin 86 (3): 638-41. [?/Please provide]

Rotimi, Charles. 2004. Are medical and nonmedical uses of large-scale genomic markers conflating genetics and 'race'? Nature Genetics 36 (11): 543-47.

Sankar, Pamela, Mildred Cho, Celeste Condit, Linda Hunt, Barbara Koenig, Patricia Marshall, Sandra Soo-Jin Lee, and Paul Spicer. [?/The ANNALS lists up to 10 authors; please add full first name and last name for 9 more authors] 2004. Genetic research and health disparities. JAMA 291 (24): 2985-89.

Shiao, Jiannbin Lee, Thomas Bode, Amber Beyer, and Daniel Selvig. [?/The ANNALS lists up to 10 authors; please add full first name and last name for 9 more authors] 2012. The genomic challenge to the social construction of race. Sociological Theory 30 (2): 67-88.

SIGMA Type 2 Diabetes Consortium. 2014. Sequence variants in Slc16all are a common risk factor for Type 2 Diabetes in Mexico. Nature 506 (February): 97-101.

Simons, Ronald,Man Kit Lei, Steven Beach, Gene Brody, Robert Philibert, and Frederick Gibbons. [?/The ANNALS lists up to 10 authors; please add full first name and last name for 9 more authors] 2011. Social environment, genes, and aggression: Evidence supporting the differential susceptibility perspective. American Sociological Review 76 (6): 883-912. 
Sternberg, Robert,Elena Grigorenko, and Kenneth Kidd. [?/The ANNALS lists up to 10 authors; please add full first name and last name for 9 more authors] 2005. Intelligence, race, and genetics. American Psychologist 60 (1): 46-59.

Suhay, Elizabeth, and Toby Jayaratne. 2012. Does biology justify ideology? The politics of genetic attribution. Public Opinion Quarterly 77 (2): 497-521.

Urban, D., and T. Hoban. [?/First names required] 1997. Cognitive determinants of risk perceptions associated with biotechnology. Scientometrics 40 (2): 299-331. JLH: first names are not included in the published article

Wade, Nicholas. 2014. A troublesome inheritance: Genes, race and human history. New York, NY: Penguin Press.

\section{Notes}

\footnotetext{
${ }^{\mathrm{i}}$ How to define race and ethnicity, or to place individuals within a particular group, are vexed questions with no consensual or correct answers. This article treats the two terms as essentially synonymous. That decision was driven by the need to keep phrasing in a public opinion survey simple, given the facts that some respondents have little schooling or do not use English or Spanish as their first language, and thatthe question is asking about complex or abstract issues such as genetic inheritance. Knowledge Networksfollows the U.S. federal government's policy of asking separately about the respondent's self-identified race (black, white, Asian, more than one race) and Hispanicity. However, along with many other survey analyses, we treat Hispanics as a non-overlapping group comparable to whites, blacks, and Asians. We typically use the phrase "racial or ethnic group" to remind readers that the two terms are somewhat blurred conceptually.

${ }^{i i}$ We thank two anonymous reviewers for helping us to clarify phrasing here and elsewhere in the article.

iii Geneticists have recently shown that epigenetics - the impact of environment on genes within an individual or across generations through genetic inheritance — better explains many human phenotypes than does either "nature" or "nurture" alone. Eventually the old dichotomy may disappear from broad societal frameworks as it has largely
} 
disappeared among experts. But the interactive concept of epigenetics is only beginning to diffuse into society, so use the old dichotomy to frame our analysis of American public opinion about genomic science.

${ }^{\text {iv }}$ We use the phrase "technology optimism or pessimism" because it is commonly employed in the literature on risk acceptance or avoidance. But like the terms "race" or "ethnicity," this terminology carries with baggage that we hope to set aside. That is, we focus mainly on technological uses of science, but we cannot be certain that survey respondents distinguish between science and the societal use of science. The distinction is not crucial for our analysis; the reader can substitute "risk acceptance or avoidance" or "preference for Type I or Type II errors" if that clarifies our framing.

${ }^{\mathrm{v}}$ The National Institute of Diabetes and Digestive and Kidney Diseases

${ }^{\text {vi }}$ A reviewer pointed out that, despite the NIH's explicit commitment to social constructivist understandings of race, "in practice much of their work and funding are oriented around assumptions of a genetic base to race or ethnicity." For example, the NIH's encouragement to disaggregate data into the Census Bureau's racial and ethnic categories can be understood either as a way to ensure attention to people in small or disadvantaged social categories, or as an implicit statement that race and ethnicity are substantively meaningful categories for understanding and analyzing genetic data. (For the latter claims, see Epstein [2007]; Sankar et al. [2004]). This is an important issue for public policy, and it explains our cautious phrasing of "self-presentation" and "portrays itself." Nonetheless, for our purposes the NIH's self-presentation suffices to illustrate cell 4 of the analytic framework.

vii The choices were: white, black or African American, American Indian or Alaska Native, Asian, Native Hawaiian or Pacific Islander, and two or more races. A separate item asked respondents if they were of Hispanic origin. As we noted above, our analysis of GKAP treats respondents who identified as Hispanic (regardless of their race) as a group distinct from non-Hispanic whites, non-Hispanic blacks, and so on.

viii The reverse logic — judging the possible benefits of genomics research and then deciding if phenotypes are especially prevalent in one group due to genetic inheritance—seems much less plausible. It is, of course, possible that both technology optimism and views of group-inflected genetic inheritance are shaped by a third factor, such as education, religious commitments, or scientific literacy.

${ }^{\text {ix }}$ Bliss also emphasizes another important point: "Even if that framework took hold in the public, there would still be the problem of over-focusing on the genetics at the expense of sociological factors" (communication with the authors, January 25, 2015). 
${ }^{\mathrm{x}}$ See http://www.africanancestry.com/our-story. 